\title{
CARACTERIZAÇÃO GEOQUÍMICA PRELIMINAR DOS GRANITÓIDES AFLORANTES NAS VIZINHANÇAS DO BATÓLITO PINHAL-IPUIÚNA (SP-MG)
}

\author{
REGINA C. HADDAD*; VALDECIR A. JANASI** \& HORSTPETER H. G. J. ULBRICH**
}

\begin{abstract}
PRELIMINARY GEOCHEMICAL CHARACTERIZATION OF GRANITOIDS OUTCROPPING NEXT TO THE PINHAL-IPUIUUNA BATHOLITH (SP-MG) Three groups of granitic rocks outcropping in the neihbourhood of the calc-alkaline Pinhal-Ipuiúna batholith. (BPI) were considered genetically and/or temporally unrelated to the main body of the batholith on the basis of field and petrographic criteria. They correspond to porphyritic biotite monzogranites and granodiorites, equigranular to inequigranular anatectic granites ("Pinhal-type granites") as well as hornblende-biotite monzonites that make up a small body named Maravilha Monzonitic Massif. The porphyritic biotite granitoids are heterogeneous, foliated rocks distinguished from the BPI granitoids by the lack of amphibole and close association with the anatectic equigranular granites. The latter, in turn, are represented by fine- to medium-grained monzo- and syenogranites strongly heterogeneous in the outcrop; they are closely related to regional migmatites and are interpreted as results of crustal anatexis. The Maravilha Monzonitic Massif is formed by medium- to coarse-grained hornblende-biotite monzonites and biotite quartz monzonites showing well-developed flow foliation. The porphyritic biotite granitoids are chemically distinguished from similar rocks of the BPI only due to their higher $\mathrm{Fe}$ and lower $\mathrm{K}$ contents, as well as higher A/CNK. Remarkable similarities in terms of trace elements, including the REE, suggest that some granodiorites migth have some kind of relationship with the BPI, although if this is the case they should be derived from different (less potassic) magmas. On the other hand, textural and field aspects suggest that any genetic relationships between the monzogranites that are predominam in this unity and the BPI are highly improbable. The Pinhal-type granites are easily distinguished from differentiated granites from the $\mathrm{BPI}$ by their lower $\mathrm{Ca}$, Sr and $\mathrm{Cr}$, higher $\mathrm{Fe}, \mathrm{Zr}$ and $\mathrm{Rb}$, as well as more fractioned REE patterns. Two subgroups of Pinhal-type granites that are recognized on the basis of their acessory minerais are chemically different; the subgroup showing allanite and titanite as important accessories hás more fractioned REE patterns displaying pronounced

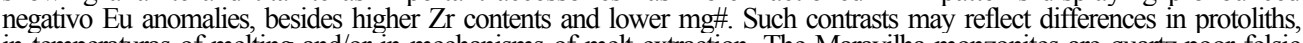
in temperaturas of melting and/or in mechanisms of melt extraction. The Maravilha monzonites are quartz-poor felsic rocks of uncertain stratigraphic position with a very peculiar chemical signature, specially their strongly fractionated REE patterns and high $\mathrm{Ba}$, Sr and $\mathrm{Zr}$ contents.
\end{abstract}

Keywords: Granite, monzonitic rocks, igneous petrology, whole-rock chemistry.

RESUMO Três conjuntos de rochas graníticas aflorantes nas vizinhancas do batólito granítico cálcio-alcalino Pinhal-Ipuiúna (BPI- Neoproterozóico; ca. 650 Ma?) foram considerados, através de critérios de campo e petrográficos, desvinculados genética e/ou temporalmente do conjunto principal do batólito. Correspondem a biotita monzogranitos a granodioritos porfiríticos, granitos equigranulares a inequigranulares anatéticos ("granitos tipo Pinhal") e hornblenda-biotita monzonitos que formam um pequeno corpo designado Macico Monzonítico Maravilha. Os biotita granitóides porfiríticos são rochas heterogêneas, foliadas, que se distinguem dos granitóides do BPI pela ausência total de anfibólio e íntima associação com granitos equigranulares anatéticos. Estes, por sua vez, são representados por monzo-e sienogranitos finos a médios, bastante heterogêneos, relacionados aos migmatitos regionais e interpretados como de geração polifásica, resultantes de anatexia crustal. O Maciço Monzonítico Maravilha é formado por hornblenda-biotita monzonitos e biotita quartzo monzonitos inequigranulares médios a grossos, com foliação de fluxo bem desenvolvida. Os biotita granitóides porfiríticos distinguem-se quimicamente de termos similares do BPI apenas por seus teores mais altos de Fe, mais baixos de $\mathrm{K}$ e maior A/CNK. Semelhanças notáveis em termos de elementos traços, incluindo ETR, sugerem a possibilidade de algum vínculo entre os granodioritos e o BPI, embora aparentemente derivem de magmas distintos (menos potássicos); por outro lado, os aspectos texturais e de campo sugerem ser mais dificil a existência de qualquer vínculo genético entre os monzogranitos predominantes na unidade e o BPI. Os granitos tipo Pinhal se distinguem sob vários aspectos dos granitos mais diferenciados do BPI (menores conteúdos de $\mathrm{Ca}$, Sr, $\mathrm{Cr}$; maiores de $\mathrm{Fe}, \mathrm{Zr}, \mathrm{Rb}$, além de padrões de ETR mais fracionados). Dois conjuntos de granitos tipo Pinhal diferenciados com base na mineralogia acessória são quimicamente distintos; o conjunto que tem allanita e titanita como acessórios importantes se distingue por seus padrões de ETR mais fracionados e com anomalias negativas de Eu pronunciadas, além de maior conteúdo de $\mathrm{Zr}$ e mg\# mais baixo. Tais variações podem refletir diferenças de protolito, de temperatura de fusão e/ou de mecanismos de extração de magmas. Os monzonitos Maravilha são rochas félsicas pobres em quartzo, de posição estratigráfica incerta, com assinatura química bastante peculiar, em especial os padrões de ETR muito fracionados e os altos teores de Ba, Sr e Zr.

Palavras-chaves: Granitos, rochas monzoníticas, petrologia ígnea, litoquímica.

INTRODUÇÃO O Batólito granitóide Pinhal-Ipuiúna (BPI) constitui uma das mais importantes manifestações do magmatismo cálcio-alcalino potássico brasiliano no sudeste brasileiro, e foi alvo de mapeamento regional e estudos petrográficos e geoquímicos recentes (Vasconcellos \& .Janasi 1989, Haddad \& Janasi 1992, Haddad 1995, Haddad et al 1996). É constituído por um conjunto de rochas granitóides predominantemente porfiríticas de composição variável no intervalo monzodiorito-quartzo monzonito-monzogranitosienogranito, delineando uma tendência modal tipicamente cálcio-alcalina de alto potássio (Haddad 1995). O batólito ocorre encaixado em rochas metamórficas de alto grau, em geral afetadas por intensa migmatização, e o estabelecimento de uma estratigrafia para o magmatismo granitóide na sua área de ocorrência é dificultado pelo caráter polifásico da migmatização e pela presença comum de ortognaisses granitóides de idade incerta que em parte parecem constituir conjuntos mais antigos mas que, especialmente quando menos deformados e porfiríticos, podem ser de difícil distinção dos granitóides (foliados em maior ou menor intensidade) que efetivamente constituem uma associação contemporânea e grosso modo cogenética, que se pretende destacar como BPI.

* Departamento de Geociências, Instituto de Ciências Exatas, Universidade do Amazonas. Av. Gal. Rodrigo O. J. Ramos, 3000, Campus Universitário, CEP 69.077-000, Manaus, AM. Fax: (092) 644-15107 644-2227

** Instituto de Geociências, Universidade de São Paulo, Caixa Postal 11.348, CEP 05.422-970, São Paulo, SP. 
Estudos prévios têm conduzido à conclusão de que os granitos equigranulares róseos abundantes na região constituem uma associação granítica mais jovem (e.g. Hasui 1983), claramente vinculada à migmatização regional (os "granitos formadores de migmatitos" de Wernick \& Penal vá 1980) e, consequentemente, ao evento de metamorfismo que afetou os granitóides cálcio-alcalinos já consolidados. $\mathrm{O}$ presente trabalho compara, do ponto de vista petrográfico e geoquímico, granitóides representativos do BPI (cuja petrologia é abordada de modo específico e mais aprofundado em publicação a parte ora em preparação) com os granitos que foram, por critérios de campo, petrográficos e geoquímicos, considerados como temporal e/ou geneticamente desvinculados do batólito. Três conjuntos distintos são considerados: (1) biotita granitóides porfiríticos, que se diferenciam dos granitos texturamente similares do batólito pela ausência de hornblenda e associação íntima com rochas migmatíticas e podem, ao menos em parte, corresponder a rochas ortognáissicas mais antigas; (2) biotita granitos equigranulares a inequigranulares migmatíticos (granitos tipo Pinhal de Janasi \& Ulbrich $1985,1991)$ mais jovens e associados ao metamorfismo regional brasiliano (ver também Janasi 1997), e (3) hornblenda-biotita monzonitos e quartzo monzonitos que constituem um corpo semi-anelar não referido anteriormente na literatura, e designado Maciço Monzonítico Maravilha por Haddad (1995). Em vista da quantidade ainda limitada de dados geoquímicos, a abordagem aqui apresentada é de cunho preliminar, mas fundamenta algumas conclusões considera- das importantes para a caracterização do magmatismo granítico no Domínio Guaxupé.

GEOLOGIA REGIONAL O Domínio Guaxupé consiste num terreno alóctone configurado como uma Nappe de Empurrão (Campos Neto et al 1984, Campos Neto 1985), constituído por rochas de alto grau metamórfico, bastante deformadas e afetadas por processos de migmatização durante o Ciclo Brasiliano. No seu extremo norte-nordeste estão expostas rochas de níveis crustais profundos, em geral granulíticas, onde são registradas pressões de cristalização metamórfica principal superiores a $10 \mathrm{~kb}$; níveis crustais intermediários, com pressões em torno de 5-6 kbar são inferidos para o extremo meridional do alóctono, região onde afloram os granitóides do Batólito Pinhal-Ipuiúna (Vasconcellos et al. 1991). Este terreno é alóctone sobre a Faixa Dobrada Alto Rio Grande, localmente representada por sequências meta-vulcanossedimentares dos grupos Itapira e Andrelândia, de idade provável mesoproterozóica, e seu embasamento ArqueanoPaleoproterozóico.

Os conjuntos litológicos que constituem o Domínio Guaxupé no seu extremo meridional incluem rochas gnáissicomigmatíticas atribuídas aos complexos Caconde e Pinhal indivisos, granitóides cálcio-alcalinos potássicos do Batólito Pinhal-Ipuiúna e indivisos, e rochas sieníticas do Maciço Pedra Branca, além das três associações de rochas granitóides individualizadas neste trabalho (Fig. 1).

As rochas supracrustais gnáissico-migmatíticas do Complexo Caconde constituem um pacote metassedimentar domi-

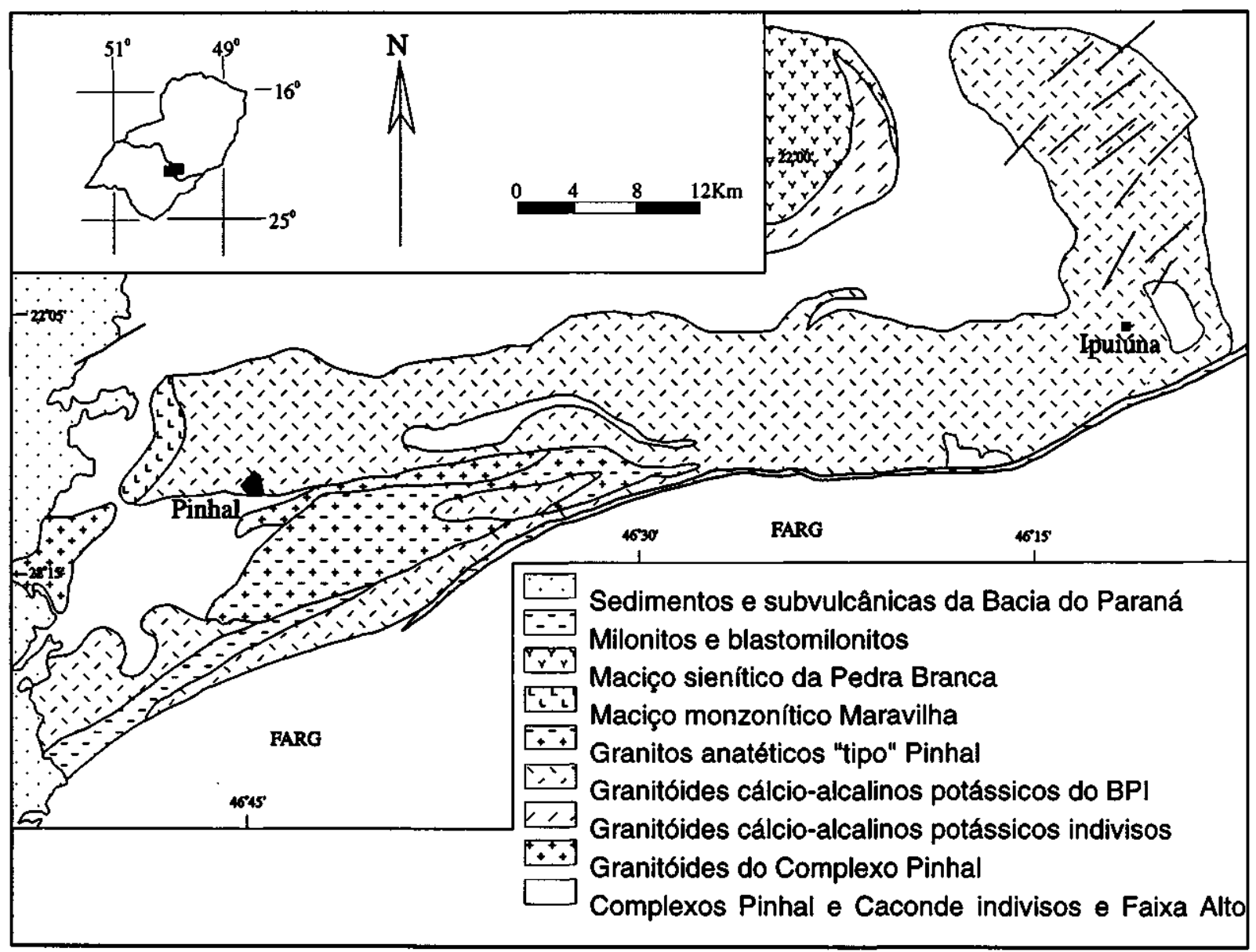

Figura 1 - Mapa geológico simplificado da região entre Pinhal e Ipuiúna mostrando o contorno do Batólito Pinhal-Ipuiúna e as ocorrências de outros granitóides.

Figure 1-Simplified geological map of the Pinhal-Ipuiúna region showing the outline of the homonimous batholith and the ocorrences of other granitoids. 
nado por biotita gnaisses finos a médios, migmatíticos, contendo ou não granada, com níveis de sillimanita-mica xistos feldspáticos e intercalações de rochas cálcio-silicáticas, com frequência invadidos por granitos equigranulares finos a médios.

Ortognaisses variados, incluindo (clinopiroxênio)-hornblenda-biotita gnaisses tonalíticos inequigranulares, gnaisses leucograníticos brancos equigranulares, e vários tipos de biotita gnaisses, em parte ocelares e migmatíticos, constituem as rochas dominantes do Complexo Pinhal.

Os granitóides atribuídos ao BPI são predominantemente porfiríticos e exibem foliação dada por alinhamento de megacristais de feldspato alcalino, além de intenso estiramento de quartzo e minerais máficos. Foram reunidos em três unidades maiores, com base em suas composições: São José da Prata (monzodioritos com índice de cor (IC) em geral superior a 20), Ipuiúna (quartzo monzonitos e monzogranitos com IC entre 10 e 15) e Serra do Pau d'Alho (monzo- e sienogranitos com IC $<10$, em geral $<5$ ). Cada uma dessas unidades inclui uma ampla variedade de fácies, que se distribuem em diferentes porções do batólito. A sequência de intrusão é, em geral, das fácies mais máficas para as mais félsicas, mas não é certo se as fácies reunidas na mesma unidade obedecem sempre a mesma ordem; mesmo o vínculo genético e temporal de algumas fácies mais félsicas com as demais não pôde, até o momento, ser definitivamente estabelecido (Haddad 1995, Haddad et al. em preparação).

O maciço Pedra Branca é constituído por uma variedade de sienitos potássicos, que inclui tipos saturados com augita sódica a egirina-augita, flogopita e titanita, e tipos supersaturados com augita e biotita (Winters 1981, Janasi 1996), e é circundado por um anel de granitos mais antigos, com predomínio de leucogranitos porfiríticos similares aos tipos mais diferenciados presentes no BPI.

\section{GEOLOGIA E PETROGRAFIA DOS GRANITOS} ESTUDADOS Biotita granitóides porfiríticos Trata-se de rochas foliadas, com megacristais de feldspato alcalino rosado de dimensões e formas muito variadas (em geral alongados, com 2-3 cm, mas ocasionalmente com seções quadradas e alcançando até $4-5 \mathrm{~cm}$ ), e por vezes distribuídos de forma batante heterogénea em matriz cinzenta equigranular média. Afloram em um corpo principal alongado na direção $\mathrm{E}-\mathrm{W}$, diretamente em contato com as rochas do Batólito Pinhal-Ipuiúna (BPI), a sul-sudeste da cidade de Pinhal (SP). Formam ainda um outro corpo mais a oeste, em contato com rochas da Bacia do Paraná (Fig. 1), e também constituem ocorrências pontuais ao longo da rodovia PinhalMogi Guaçu. Ocorrem em íntima associação com volumes expressivos de granitos equigranulares tipo Pinhal, e têm biotita como principal mineral máfico. $\mathbf{O}$ principal contraste mineralógico em relação aos granitos da unidade Ipuiúna do BPI é a ausência de hornblenda, além da presença ocasional de granada secundária (e.g. amostra PH-83C).

Análises modais de granitos desta unidade foram feitas em fatias de rocha submetidas a ensaios de colorimetria seletiva de feldspatos. Em vista de seu caráter heterogéneo e das dimensões dos megacristais de feldspato alcalino, foram utilizadas várias fatias totalizando áreas entre 200 e $500 \mathrm{~cm}^{2}$ e fpram contados entre 1100 e 3000 pontos, aproximadamente. Para diferenciação entre os minerais máficos, as análises foram complementadas por contagens em lâminas delgadas. Os resultados obtidos são apresentados na Tabela 1 e representados no diagrama Q-A-P da Fig. 2, juntamente com algumas análises modais dos granitóides do BPI; três das amostras analisadas são monzogranitos com IC entre 7 e 12, enquanto a amostra $\mathrm{PH}-192$ tem composição granodiorítica e $\mathrm{IC}=14$.

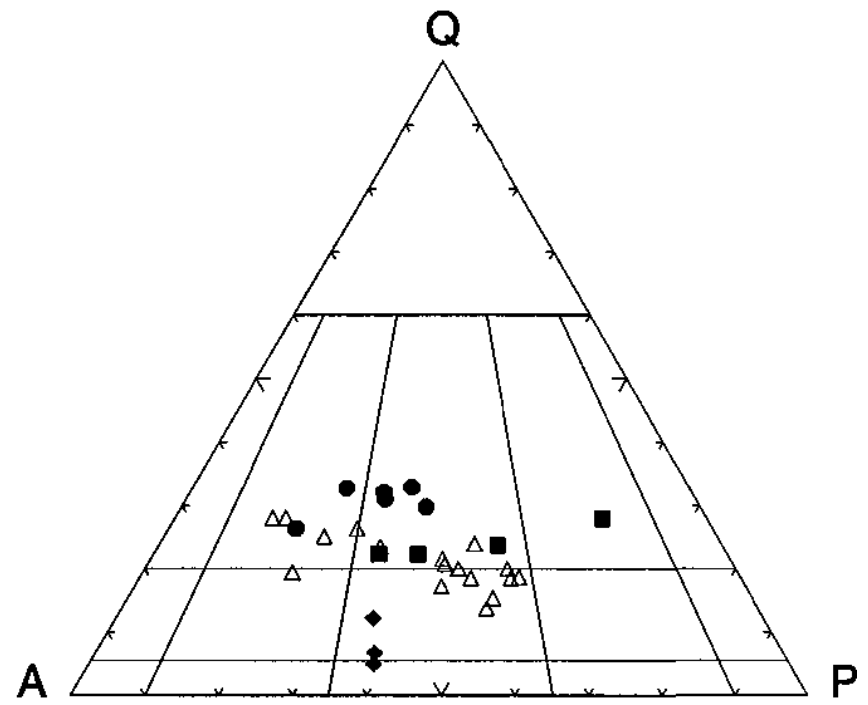

Figura 2 - Distribuição das modas de rochas do Batólito Pinhal-Ipuiúna (BPI) e granitóides circunvizinhos no diagrama QAP. Símbolos: triângulos vazios $=$ granitóides do BPI; quadrados cheios = biotita granitóides porfiriticos; círculos cheios = granitos tipo Pinhal; losangos cheios = monzonitos Maravilha.

Figure 2 - Distribution of the modes of rocks from the Pinhal-Ipuiúna batholith (BPI) and adjacent granitoids in the QAP diagram. Symbols: open triangles = BPI granitoids; closed squares = porphyritic biotite granitoids; closed circles $=$ Pinhal-type granites; closed diamonds = Maravilha monzonites.

Os biotita monzogranitos (bmp; Tab. 1) são os tipos predominantes e se caracterizam, no campo, pela distribuição muito heterogénea dos megacristais de feldspato alcalino e pela ocorrência junto a granitos equigranulares nebulíticos mais claros (tipo Pinhal, ver adiante).

O feldspato alcalino pertítico ocorre predominantemente como megacristais de seção retangular a quadrada com 3 a 6 $\mathrm{cm}$ de comprimento máximo, mas também é abundante na matriz. O plagioclásio é andesina, e por vezes mostra algum zoneamento $\left(\mathrm{An}_{40}\right.$ a $\left.\mathrm{An}_{30}\right)$. A biotita $(\mathrm{X}=\mathrm{Y}=$ marrom-avermelhado; $Z=$ castanho claro) mostra transformação parcial para clorita, que é acompanhada pelo desenvolvimento de epidoto secundário. Minerais opacos, apatita, zircão, titanita e allanita são os principais acessórios, geralmente associados a agregados de biotita. Localmente estas rochas podem desenvolver uma paragênese retrometamórfica, evidenciada pela pronunciada saussuritização do plagioclásio, em parte substituído por granada secundária, e pela cloritização generalizada da biotita. A granada, levemente rosada, aparece como "manchas" irregulares ou mesmo grãos xenomórficos mais desenvolvidos e muito fraturados, em geral confinados ao interior dos cristais de plagioclásio mais intensamente saussuritizados.

Os biotita granodioritos caracterizam-se pela distribuição menos irregular e dimensões máximas um pouco menores $(2-3 \mathrm{~cm})$ dos megacristais de feldspato alcalino, mineral que em geral está ausente na matriz. É comum em alguns afloramentos a presença de enclaves ou schlieren máficos, de composição diorítica $s . l$. e granulação fina a média, alongados segundo a foliação do granodiorito e exibindo contatos irregulares. Em alguns enclaves observa-se a presença de megacristais de feldspato alcalino semelhantes aos encontrados no granitóide hospedeiro, sugerindo tratar-se de vestígios de magmas básicos-intermediários de cristalização contemporânea às rochas granitóides. 
Tabela 1 - Análises modais de biotita granitóides porfiriticos, de granitos tipo Pinhal e monzonitos Maravilha.

Table 1 - Modal analyses of porphyritic biotite granitoids, Pinhal-type granites and Maravilha monzonites.

\begin{tabular}{|c|c|c|c|c|c|c|c|c|c|c|c|c|c|}
\hline \multirow[b]{2}{*}{ Fácies } & \multicolumn{4}{|c|}{ Biotita Granitoides Porfiríticos } & \multicolumn{7}{|c|}{ Granitos tipo Pinhal } & \multicolumn{2}{|c|}{$\begin{array}{l}\text { Monzonitos } \\
\text { Maravilha }\end{array}$} \\
\hline & BMP & BMP & BMGP & BMGP & BGE & BGE & BGE/I & BGE/ & BGE/I & BGE/I & HBM & HBM & BQM \\
\hline Amostra & PH-83C & PH-11 & PH-192 & PH-185 & SC-77A & SC-77B & PH-182B & PH-12C & PH-182A & PH-200 & PH-187 & PH-173A & PH-190 \\
\hline Quartzo & 22,1 & 20,8 & 24,1 & 21,0 & 30,8 & 27,1 & 29,1 & 27,9 & 26,1 & 24,6 & 6,1 & 4,4 & 11,6 \\
\hline Feldspato Alcalino & 41,8 & 39,2 & 12,3 & 26,9 & 43,5 & 30,9 & 37,6 & 37,8 & 32,5 & 52,5 & 50,8 & 50,9 & 50,4 \\
\hline Plagioclásio & 26,5 & 33,2 & 49,7 & 40,2 & 19,5 & 24,3 & 23,6 & 24,1 & 28,8 & 16,0 & 34,4 & 34,5 & 33,0 \\
\hline Biotita & 7,4 & 5,3 & 12,2 & 10,6 & 4,8 & 15,4 & 7,3 & 6,5 & 8,7 & 5,1 & 6,0 & 5,7 & 3,3 \\
\hline Hornblenda & nd & nd & nd & nd & nd & nd & nd & nd & nd & nd & nd & 1,9 & nd \\
\hline Opacos & 1,0 & 1,0 & 0,9 & 0,8 & 1.0 & 2,0 & 1,8 & 2,3 & 2,3 & 0,8 & 1,9 & 1,6 & 1,0 \\
\hline Apatita & 0,2 & 0,2 & 0,3 & 0,2 & 0,2 & 0,2 & 0,3 & 0,2 & 0,2 & 0,2 & 0,6 & 0,6 & 0,2 \\
\hline Granada & 0,7 & nd & nd & nd & nd & nd & nd & nd & nd & nd & nd & nd & nd \\
\hline Outrós* & 0,3 & 0,3 & 0,5 & 0,2 & tr & tr & $0.2^{\text {al }}$ & $1,2^{\mathrm{al}}$ & $1,3^{\mathrm{ti}}$ & $0,7^{\mathrm{i}}$ & 0,1 & 0,4 & 0,5 \\
\hline Total & 100,0 & 100,0 & 100,0 & 99,9 & 99,9 & 99,9 & 99,9 & 100,0 & 99,9 & 99,9 & 99,9 & 100,0 & 100,0 \\
\hline Indice de Cor & 9,6 & 6,8 & 13,9 & 11,8 & 6,1 & 17,6 & 9,6 & 10,2 & 12,5 & 6,8 & 8,6 & 10,2 & 5,0 \\
\hline$N^{1}$ Pontos (FR) & 2.000 & 3.017 & 3.070 & 1.428 & - & - & - & - & - & 1.097 & 2,380 & 2.800 & 560 \\
\hline Área $\left(\mathrm{cm}^{2}\right)$ & 320 & 483 & 491 & 228 & - & - & - & - & - & 175 & 381 & 448 & 90 \\
\hline$\overline{N^{2} \text { Pontos (LD) }}$ & 1.180 & 730 & 1.383 & 1.220 & 2.000 & 1.900 & 2.500 & 2.335 & 3.200 & 590 & 897 & 1.170 & 680 \\
\hline
\end{tabular}

FR: análises modais macroscópicas em fatias de rochas. LD: análises modais microscópicas em lâminas delgadas. * = Epidoto, titanita, allanita, zircão.

al $f \mathrm{i}$ = Principalmente allanita/titanita. $\mathrm{nd}=$ não detectado; $\mathrm{tr}=$ traços.

Abreviações para as fácies: $\mathrm{BMP}=$ biotita monzogranitos porfiríticos. $\mathrm{BMGP}=$ biotita monzogranitos a granodiorítos porfiríticos. $\mathrm{BGE}=$ biotita granitos

equigranulares. $\mathrm{BGE} / \mathrm{I}=$ biotita granitos equigranulares a inequigranulares. $\mathrm{HBM}=$ hornblenda-biotita monzonitos. $\mathrm{BQM}=$ biotita

quartzo monzonitos.

Ao exame microscópico, os granodioritos mostram maior evidência dos processos de transformações pós-magmáticas dos feldspatos, principalmente na abundância de plagioclásio mirmequítico envolvendo localmente os cristais maiores de feldspato alcalino, em geral pertíticos. O plagioclásio é o componente principal da matriz, com composição de andesina sódica $\left(\mathrm{An}_{34}\right.$ e $\left.\mathrm{An}_{30}\right)$. Biotita marrom a castanha clara, cuja transformação local para clorita + epidoto + minerais opacos é frequente, constitui o principal mineral máfico. Os acessórios são representados principalmente pelos minerais opacos, apatita e zircão.

Biotita granitos equigranulares a inequigranulares migmatíticos Os granitos anatéticos tipo Pinhal ocorrem como uma série de pequenos corpos, em sua maioria não mapeáveis, intrusivos tanto nos gnaisses migmatíticos regionais quanto nas rochas do BPI; as ocorrências de maior expressão se localizam na porção sudoeste da área representada no mapa geológico (Fig. 1). Trata-se de granitos equigranulares a inequigranulares róseos a róseo-acinzentados, petrograficamente heterogêneos, em geral pouco foliados. São interpretados como produtos de anatexia crustal ("granitos formadores de migmatitos" de Wernick \& Penalva 1980) em vista da íntima associação com migmatitos que exibem leucossomas texturalmente idênticos a eles, da frequência de estruturas schlieren e nebulíticas, além da presença comum de xenólitos de rochas gnáissicas. A heterogeneidade petrográfica manifesta-se especialmente em variações no IC e na textura; com frequência, coexistem em um mesmo afloramento tipos mais escuros (cinza-rosados) inequigranulares que são invadidos, por vezes de forma difusa, por tipos equigranulares róseos mais claros (e.g. pontos SC77 e PH-182; cf.Tabela 1).

As análises modais foram feitas em lâminas delgadas, exceto em uma amostra de granulação mais grossa, na qual foi feita contagem em fatia de rocha (Tab. 1). As composições são normalmente monzograníticas, com teores de quartzo ligeiramente superiores aos dos demais granitos estudados (Fig. 2); uma amostra (PH-200) é mais pobre em quartzo e adentra francamente o campo sienogranítico $(>50 \%$ de feldspato alcalino modal). Os IC variam entre 6 e 10, exceto nas amostras mais máficas dos afloramentos SC-77 e PH-182, onde o IC chega a 18 e 12, respectivamente. As amostras mais félsicas desses mesmos afloramentos são ligeiramente mais ricas em quartzo e em feldspato alcalino que as mais máficas associadas; a SC-77A chega a adentrar o campo dos sienogranitos(Tab. 1; Fig. 2).

Os granitos tipo Pinhal podem ser agrupados, em função da quantidade e presença de minerais acessórios característi$\mathrm{cos}$, em dois conjuntos distintos (Tab. 1). $\mathrm{O}$ primeiro inclui os termos dominantemente equigranulares (bge), cujos acessórios são representados dominantemente pelos minerais opacos, zircão e apatita. O segundo é constituído por granitos equigranulares a inequigranulares (bge/i) finos a médios, que têm titanita e allanita como acessórios relativamente abundantes, ao lado dos minerais opacos, zircão e apatita.

Os granitos equigranulares (bge) aparecem, em geral, como ocorrências pontuais na área de domínio dos biotita gnaisses migmatíticos do Complexo Pinhal, ao norte da extensão E-W do BPI, além de formarem pequenos corpos que invadem os granitóides do batólito no seu extremo oeste. Já os termos equigranulares a inequigranulares (bge/i) constituem corpos mapeáveis que predominam na porção sudoeste da 
área, onde podem ocorrer associados aos biotita granitóides porfiríticos anteriormente descritos, além de formarem pequenos corpos intrusivos nas rochas da porção centro-sul do BPI.

A composição mineralógica essencial dos dois grupos não apresenta variações significativas, e as texturas granulares panxenomórficas predominantes sugerem a cristalização essencialmente simultânea da maior parte do volume de feldspatos (microclínio pertítico e plagioclásio $A_{30-26}$ ) e quartzo. Feições de deformação mais pronunciadas estão presentes em amostras próximas à zona de cisalhamento de Jacutinga, com a geração de faixas microcristalinas, constituídas por fragmentos de feldspato alcalino e quartzo \pm biotita \pm plagioclásio.

\section{Hornblenda-biotita monzonitos e quartzo} monzonitos $\mathrm{O}$ Maciço Monzonítico Maravilha (Fig. 1) corresponde a um cçrpo semi-circular que limita, a oeste, os granitóides do BPI. E constituído por monzonitos a quartzo monzonitos médios a grossos, com foliação de fluxo bem desenvolvida. Seu aspecto textural lembra os sienitos laminados dos maciços Capituva e Pedra Branca (Janasi 1992), e suas relações de idade com os demais granitóides são ainda pouco claras, em virtude da carência de estudos específicos. Rochas dioríticas foliadas ocorrem associadas, formando corpos tabulares métricos e enclaves centimétricos que podem gradar lateralmente para schlieren biotíticos.

$\mathrm{O}$ maciço é formado por (hornblenda)-biotita monzonitos (hbm), que perfazem a quase totalidade do corpo, e biotita quartzo monzonitos (bqm), com ocorrência localizada na sua porção sul. Os primeiros são rochas inequigranulares médias a grossas, foliadas, com teor em minerais máficos entre 8 e $10 \%$, e estrutura laminada evidenciada pela orientação preferencial dos cristais tabulares de feldspato alcalino, enquanto os últimos distinguem-se pela textura equigranular média e pelo menor IC (em torno de 5; Tab. 1).

Em seção delgada a mineralogia de ambas as fácies é a mesma, exceção feita ao anfibólio, ausente nos quartzo monzonitos. As texturas magmáticas originais estão em parte mascaradas pela presença de uma geração de grãos menores de quartzo e plagioclásio mirmequítico recristalizados $( \pm$ biotita \pm minerais opacos), intersticial aos grãos maiores de feldspato. São constituídos essencialmente por feldspato alcalino pertítico ou micropertítico, plagioclásio com composição dominante no intervalo de $\mathrm{An}_{40-36}$ para os monzonitos e $\mathrm{An}_{30-26}$ para os quartzo monzonitos, com biotita marrom a castanha clara predominante sobre hornblenda verde a castanha. Os minerais opacos (hemo-ilmenita, magnetita e pirita) são os acessórios mais abundantes, ao lado de allanita, titanita, apatita e zircão.

GEOQUÍMICA DE ROCHAS Métodos analíticos Amostras dos granitóides aflorantes nas vizinhanças do BPI foram britadas em britador de mandíbulas de aço, quarteadas e pulverizadas até $<200$ mesh em moinho de ágata do tipo planetário. Visando garantir a representatividade das análises dos tipos porfiríticos, estas rochas foram britadas em quantidades sempre superiores a $8 \mathrm{~kg}$; para as demais, de granulação média ou fina e em geral equigranulares, amostras entre 1 e $3 \mathrm{~kg}$ foram consideradas representativas.

As análises de elementos maiores, menores e traços selecionados (Ba, Sr, Zr, La, Y e V) foram feitas por ICP-AES a partir de soluções obtidas por fusão alcalina de $0,25 \mathrm{~g}$ de amostra; a metodologia empregada na solubilização, calibração e análise, além dos limites de detecção e procedimentos de correção adotados no Laboratório do Departamento de Mineralogia e Petrologia do IG-USP são descritos em Janasi et al. (1996). Elementos terras raras foram analisados em três amostras por ICP-AES no Laboratório da Geolab em Belo
Horizonte, Minas Gerais. Os elementos U, Th, Sc, Cs, Hf e Ta foram analisados em amostras selecionadas, por ativação neutrônica no Activation Laboratories, Canadá; duas dessas análises incluíram também os ETR. Elementos traços adicionais foram analisados por FRX, no Centro de Pesquisas Geocronológicas do IG-USP (Rb) e no Geolab (Nb, Cr e Ni),

Apresentação dos resultados Os resultados das análises químicas obtidos em 3 amostras dos biotita granitóides porfiríticos, 5 amostras dos granitos equigranulares tipo Pinhal e 2 amostras de monzonitos do maciço Maravilha são apresentados na Tabela 2. São também apresentadas, para comparação, análises de 5 amostras representativas das principais unidades do BPI

Nos diagramas de variação utilizando $\mathrm{SiO}_{2}$ como indicador de diferenciação apresentados nas Figuras 3 e 4, além das amostras apresentadas na Tabela 2, foram adicionadas 12 amostras de rochas do BPI (Haddad et al, em preparação), a fim de delinear a tendência geral dos granitóides do batólito.

Os biotita granitóides porfiríticos acompanham, no geral, a tendência composicional do BPI, mas se diferenciam pelos teores ligeiramente mais elevados de $\mathrm{Fe}_{2} \mathrm{O}_{3}$ (e consequentes menores $\mathbf{m g} \#=\mathrm{Mg} /(\mathrm{Mg}+\mathrm{Fe}$ total $))$ e relativamente mais baixos de $\mathrm{K}_{2} \mathrm{O}$ (Fig. 3). O granodiorito $\mathrm{PH}-192$ tem padrão de ETR muito similar ao dos quartzo monzonitos do BPI $\left(\mathrm{La} / \mathrm{Yb}_{(\mathrm{n})} \cong 20\right.$; Eu/Eu* ${ }_{(\mathrm{n})}=0,62$; Fig. 5A), o que, ao lado de várias outras similaridades em termos de elementos maiores e traços (Figs. 3, 6A) pode ser sugestivo de algum vínculo genético. A possibilidade de que esses granodioritos representem uma fácies de borda resultante de contaminação dos quartzo monzonitos do batólito não pode, portanto, ser destacada. Os dados químicos requereriam a assimilação de material mais reduzido e peraluminoso para explicar o menor mg\# (35 vs. valores médios de 40 nos quartzo monzonitos) e A/CNK > 1,0 da amostra PH-192; o teor extrememente baixo de $\mathrm{K}$, evidenciado tanto pela moda quanto pela química desta amostra, no entanto, é difícil de conciliar com esta hipótese.

Os granitos tipo Pinhal são rochas relativamente fracionadas $\left(\mathrm{SiO}_{2}=69-74 \%\right)$ e com A/CNK no limite entre os campos metaluminoso e peraluminoso $(0,97-1,03)$. Se comparados à tendência do BPI apresentam proporções mais elevadas de $\mathrm{Fe}_{2} \mathrm{O}_{3}$ (refletidas em mg\# entre 25 e 30, excetuada a amostra mais máfica $\mathrm{SC}-77 \mathrm{~B}$ ) e mais reduzidas de $\mathrm{CaO}$, quando comparados aos granitóides do Batólito PinhalIpuiúna com conteúdo equivalente em $\mathrm{SiO}_{2}$ (Fig. 3). As diferenças em termos de elementos traços são também evidentes, em particular com relação aos teores de $\mathrm{Zr}, \mathrm{Hf}, \mathrm{Rb}$ (mais altos), $\mathrm{Sr}$ e $\mathrm{Cr}$ (mais baixos; Fig. 4).

Diferenças sistemáticas entre as unidades bge e bge/i são também observadas; o primeiro conjunto, representado pelas duas amostras do afloramento SC-77, além do mg\# mais alto, é mais pobre em $\mathrm{Zr}$, La e Th. Por outro lado, as amostras da unidade bge/i analisadas para ETR exibem padrão fortemente fracionado, refletindo a presença de abundante allanita; já a amostra SC-77B tem padrão sensivelmente menos fracionado e anomalia negativa de Eu pouco pronunciada (Figs. 5B, 6B).

As rochas do Maciço Monzonítico Maravilha são quimicamente muito distintas das demais rochas estudadas. Os baixos conteúdos de quartzo a despeito de seu caráter relativamente fracionado $(\mathrm{IC}<10)$ se reíletem no não alinhamento das duas amostras analisadas com quaisquer dos outros granitóides nos diagramas de variação apresentados: ambas são mais ricas em elementos presentes nos feldspatos $(\mathrm{K}, \mathrm{Al}, \mathrm{Ba}$, $\mathrm{Sr})$ e mais pobres em elementos presentes em minerais máficos $(\mathrm{Mg}, \mathrm{Fe}, \mathrm{Ca}, \mathrm{Ti}, \mathrm{P}, \mathrm{V}, \mathrm{Cr})$ que granitos com teores de $\mathrm{SiO}_{2}$ similares (Figs. 3,4). Os teores de $\mathrm{Ba}$ e $\mathrm{Sr}$ são particularmente elevados (respectivamente superiores a 2600 e 1000 ppm), e os altos teores de feldspatos se refletem em $\mathrm{A} / \mathrm{CNK}$ próximos a $1(0,99$, a despeito da presença de alguma hornblenda 


\begin{tabular}{|c|c|c|c|c|c|c|c|c|c|c|c|c|c|c|c|}
\hline \multirow{2}{*}{$\begin{array}{c}\text { Unidade } \\
\text { Fácies }\end{array}$} & \multicolumn{3}{|c|}{ Granit6ides Porfiríticos } & \multicolumn{5}{|c|}{ Granitos tipo Pinhal } & \multicolumn{2}{|c|}{ Monz. Maravitha } & \multicolumn{5}{|c|}{ Batólito Pinhal-Ipuiúna } \\
\hline & BMP & BMP & BMGP & BGE & BGE & BGEI & BGE/I & BGE/ & HBM & HBM & QM & MGR & SGR & SGR & SGR \\
\hline Amostra & PH-11 & PH-83C & PH-192 & SC-77B & SC-77A & PH182A & PH-12C & PH-200 & PH173B & PH-187 & PH.145 & PH-01 & PH158A & SC-29 & PH-143 \\
\hline $\mathrm{SiO}_{2}$ & 70,44 & 72,42 & 66,56 & 69,69 & 73,29 & 70,42 & 69,64 & 70,46 & 60,62 & 62,83 & 56,09 & 64,31 & 68,91 & 72,90 & 74,78 \\
\hline $\mathrm{TiO}_{2}$ & 0,49 & 0,33 & 0,76 & 0,47 & 0,20 & 0,41 & 0,41 & 0,51 & 0,86 & 0,54 & 1,53 & 0,99 & 0,62 & 0,39 & 0,36 \\
\hline $\mathrm{Al}_{2} \mathrm{O}_{3}$ & 13,97 & 13,56 & 15,71 & 14,41 & 13,24 & 14,27 & 13,20 & 13,86 & 18,55 & 17,67 & 16,96 & 15,41 & 14,93 & 14,00 & 13,47 \\
\hline $\mathrm{Fe}_{2} \mathrm{O}_{3}$ & 3,16 & 2,79 & 4,50 & 3,46 & 1,87 & 2,86 & 2,96 & 2,68 & 4,44 & 4,24 & 7,12 & 4,73 & 3,95 & 1,84 & 1,96 \\
\hline $\mathrm{MnO}$ & 0,08 & 0,08 & 0,12 & 0,08 & 0,05 & 0,07 & 0,06 & 0,09 & 0,09 & 0,08 & 0,13 & 0,10 & 0,07 & 0,04 & 0,05 \\
\hline MgO & 0,81 & 0,58 & 1,46 & 1,08 & 0,38 & 0,47 & 0,45 & 0,55 & 1,26 & 0,95 & 2,47 & 1,66 & 0,96 & 0,42 & 0,48 \\
\hline $\mathrm{CaO}$ & 2,23 & 1,82 & 3,49 & 2,31 & 1,13 & 1,49 & 1,27 & 1,48 & 3,52 & 3,00 & 5,38 & 3,55 & 2,64 & 1,57 & 1,54 \\
\hline $\mathrm{Na}_{2} \mathrm{O}$ & 3,26 & 2,72 & 3,50 & 3,17 & 2,46 & 3,45 & 2,74 & 3,08 & 3,53 & 3,07 & 3,24 & 3,08 & 2,74 & 2,77 & 2,64 \\
\hline $\mathrm{K}_{2} \mathrm{O}$ & 4,42 & 5,06 & 2,76 & 4,52 & 6,26 & 5,23 & 6,32 & 5,94 & 6,12 & 6,77 & 3,86 & 4,68 & 5,23 & 6,21 & 5,86 \\
\hline $\mathrm{P}_{2} \mathrm{O}_{5}$ & 0,15 & 0,08 & 0,21 & 0,17 & 0,06 & 0,08 & 0,08 & 0,08 & 0,26 & 0,21 & 0,51 & 0,36 & 0,20 & 0,08 & 0,08 \\
\hline P.F. & 0,53 & 0,69 & 0,53 & 0,54 & 0,78 & 0,56 & 0,55 & 0,34 & 0,46 & 0,20 & 0,32 & 0,16 & 0,46 & 0,10 & 0,21 \\
\hline Total & 99,54 & 100.13 & 99,60 & 99,90 & 99,72 & 99,31 & 97,68 & 99,02 & 99,71 & 99,56 & 97,61 & 99,03 & 100,71 & 100,32 & 101,43 \\
\hline $\mathbf{B a}$ & 592 & 508 & 855 & 873 & 873 & 1367 & 896 & 644 & 3133 & 2575 & 1612 & 1443 & 1401 & 626 & 899 \\
\hline $\mathrm{Sr}$ & 383 & 180 & 509 & 257 & 211 & 339 & 306 & 246 & 1387 & 965 & 1006 & 821 & 704 & 320 & 485 \\
\hline $\mathbf{R b}$ & 165 & 183 & 182 & 209 & 227 & 222 & 203 & 210 & 136 & 175 & 141 & 143 & 160 & 171 & 181 \\
\hline $\mathbf{z}$ & 173 & 154 & 200 & 198 & 188 & 263 & 398 & 320 & 495 & 437 & 281 & 271 & 278 & 118 & 137 \\
\hline $\mathrm{La}$ & 39 & 30 & 54 & 40 & 25 & 131 & 210 & 86 & 123 & 69 & 55 & 77 & 62 & 97 & 67 \\
\hline $\mathrm{Nb}$ & 11 & 12 & 21 & 12 & 8 & 9 & 27 & 28 & 10 & 6 & 18 & 19 & 10 & 10 & 9 \\
\hline $\mathbf{Y}$ & 14 & 16 & 30 & 16 & $<10$ & $<10$ & 39 & 114 & 23 & 14 & 28 & 31 & 17 & 38 & 25 \\
\hline $\mathrm{Cr}$ & 14 & 12 & 21 & $7^{*}$ & $<10$ & 9 & $2^{*}$ & $<10$ & 9 & 7 & 29 & 40 & 27 & 14 & 15 \\
\hline $\mathrm{Ni}$ & 23 & 17 & 23 & $<10$ & $<10$ & 23 & 23 & $<10$ & 23 & 12 & 35 & 23 & 17 & 17 & 17 \\
\hline $\mathrm{v}$ & 41 & 23 & 73 & 45 & 28 & 21 & 20 & 23 & nd & 35 & 138 & 83 & 41 & 25 & 22 \\
\hline $\mathrm{La}$ & $\cdot$ & - & 46,03 & 48,40 & - & 115,60 & 194,00 & - & 100,80 & - & 44,90 & 75,00 & 66,50 & 79,00 & 51,50 \\
\hline $\mathrm{Ce}$ & . & - & 100,90 & 97,00 & - & 223,10 & 343,00 & - & 218,40 & - & 113,10 & 176,20 & 150,50 & 174,00 & 116,70 \\
\hline $\mathrm{Nd}$ & . & - & 40,56 & 34,00 & - & 62,75 & 112,00 & - & 87,35 & - & 59,33 & 77,74 & 56,84 & 69,75 & 46,35 \\
\hline Sm & - & - & 7,11 & 5,20 & - & 7,35 & 12,03 & - & 11,99 & - & 10,71 & 13,20 & 8,69 & 12,35 & 7,85 \\
\hline $\mathrm{Eu}$ & - & - & 1,26 & 1,30 & - & 0,93 & 1,06 & - & 2,86 & - & 2,18 & 2,16 & 1,84 & 1,43 & 1,49 \\
\hline Gd & - & - & 4,78 & 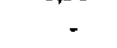 & - & 3,35 & & - & 6,18 & . & 7,11 & 8,12 & 4,95 & 7,94 & 4,84 \\
\hline $\mathrm{Tb}$ & $\cdot$ & - & & 0,70 & - & & 1,30 & - & . & - & & - & & & \\
\hline Dy & - & - & 4,22 & - & - & 1,52 & - & - & 3,27 & - & $5 ; 42$ & 6,25 & 2,92 & 6,08 & 3,34 \\
\hline $\mathrm{Er}$ & - & - & 2,10 & - & - & 0,60 & - & . & 1,26 & . & 2,60 & 2,97 & 1,28 & 2,35 & 1,57 \\
\hline $\mathbf{Y b}$ & - & - & 1,61 & 1,30 & . & 0,39 & 2,60 & - & 0,75 & . & 2,02 & 2,23 & 0,88 & 1,43 & 1,13 \\
\hline $\mathrm{Lu}$ & & & 0,19 & 0,23 & & 0,08 & 0,35 & 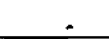 & 0,12 & & 0.25 & 0.27 & 0,15 & 0,15 & 0,16 \\
\hline Th & $\overline{-}$ & - & - & 14,70 & - & 17,80 & 23,30 & - & 9,60 & . & - & 9,80 & - & $\cdot$ & 8,70 \\
\hline $\mathrm{U}$ & $\cdot$ & - & - & 2,20 & - & 1,90 & 1,40 & . & 0,40 & - & - & 0,90 & - & - & 1,40 \\
\hline Cs & . & - & . & 3,00 & - & 1,60 & 1,60 & . & 1,20 & . & . & 1,50 & . & - & 3,10 \\
\hline Hf & . & - & . & 6,30 & - & 11,30 & 10,50 & - & 10,00 & - & - & 5,90 & . & - & 4,70 \\
\hline $\mathbf{T a}$ & $\cdot$ & - & - & 0,80 & - & 1,50 & 0,80 & . & $<0,50$ & - & - & 1,00 & - & - & .50 \\
\hline $\mathrm{Sc}$ & & & & 4.80 & & 3.20 & 2,70 & & 8,50 & & & 8.20 & 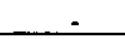 & & 4,10 \\
\hline Mg\# & 33,67 & 29,16 & 34,59 & 38,20 & 28,70 & 25,62 & 23,14 & 28,06 & 36,00 & 30,73 & 40,70 & 41,00 & 32,49 & 31,13 & 32,66 \\
\hline A $/ C N K$ & 0,98 & 1,02 & 1,02 & 1,01 & 1,03 & $\mathrm{t}, 03$ & 0,97 & 0,98 & 0.99 & 0,99 & 0.88 & 0,93 & 1,00 & 0,99 & 1,00 \\
\hline
\end{tabular}



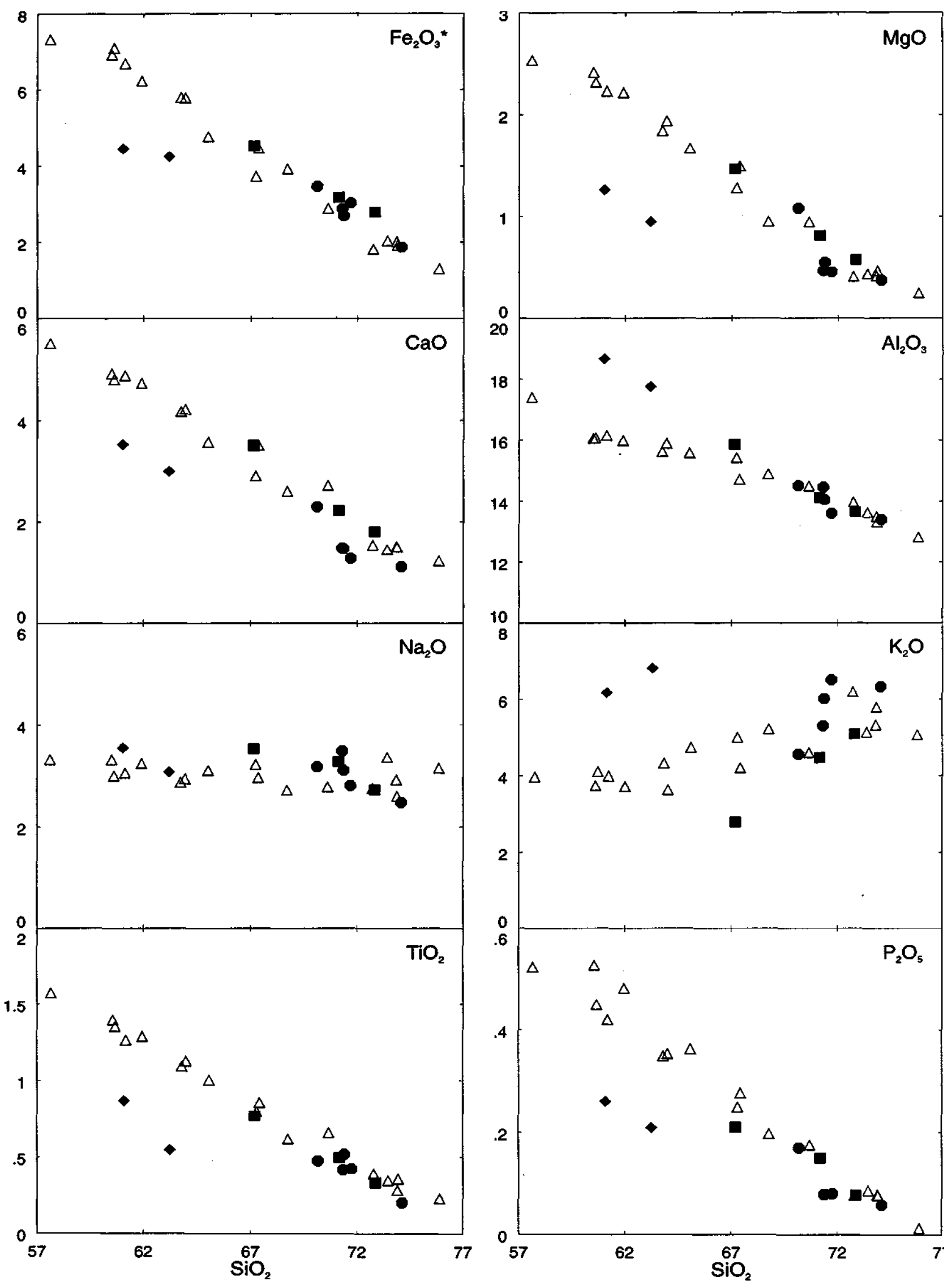

Figura 3 - Diagramas de variação $\mathrm{SiO}_{2}$ vs.óxidos maiores (\% em peso) para granitóides vizinhos ao BPI. Análises selecionadas de rochas do BPI (extraídas de Haddad, 1995) são mostradas para comparação. Símbolos como na Fig. 2.

Figure $3-\mathrm{SiO}_{2}$ vs.major oxides (all in weight $\%$ ) variation diagrams for granitoids adjacent to the BPI. Selected analyses of rocks from the BPI (from Haddad, 1995) are show for comparison. Symbols as in Fig. 2. 

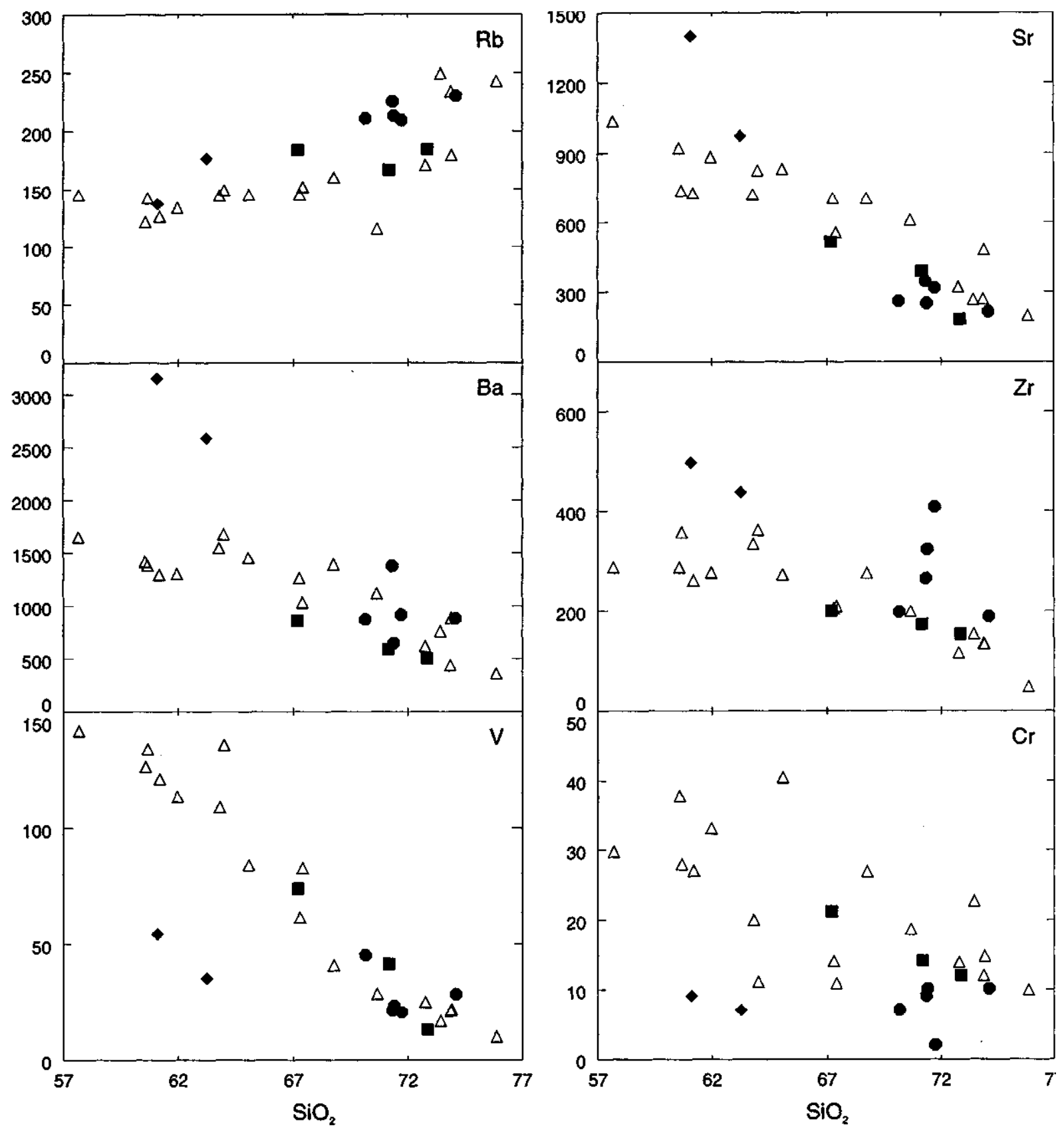

Figura 4 - Diagramas de variação $\mathrm{SiO}_{2}$ (\% em peso) vs elementos traços (em ppm) para granitóides vizinhos ao BPI. Análises selecionadas de rochas do BPI (extraídas de Haddad, 1995) são mostradas para comparação. Símbolos como na Fig. 2. Figure $4-\mathrm{SiO}_{2}$ (all in weight\%) vs.trace elements (in ppm) variation diagrams for granitoids adjacent to the BPI. Selected analyses of rocks from the BPI (from Haddad, 1995) are show for comparison. Symbols as in Fig. 2.

modal). Distinguem-se ainda das rochas do BPI pelo padrão de ETR fortemente fracionado $\left(\mathrm{La} / \mathrm{Yb}_{(\mathrm{n})} \cong 90\right)$, sem anomalia significativa de $\mathrm{Eu}\left(\mathrm{Eu} / \mathrm{Eu}_{(\mathrm{n})}=0,91\right)$, e pelos teores relativamente elevados de $\mathrm{Zr}$ e Hf (Figs. 5C, 6C).

CONSIDERAÇÕES GENÉTICAS Através de critérios petrográficos e de campo, os três conjuntos de granitos aqui estudados foram considerados genética e/ou temporalmente distintos do BPI. Os dados geoquímicos sublinham adicionalmente esta distinção, e permitem algumas considerações genéticas preliminares para essas rochas.

Os biotita granitóides porfiríticos são de distinção química mais dificil das rochas do BPI com teores de $\mathrm{SiO}_{2}$ semelhantes. Foram identificados apenas contrastes em alguns elemen- tos maiores, em particular os menores teores de $\mathrm{K}$ (refletidos na presença de granodioritos nesta unidade, composição modal ausente no BPI; cf. Haddad 1995), mg\# ligeiramente mais baixos que os típicos da unidade Ipuiúna do BPI e A/CNK mais altos, em parte superiores a 1,0 (refletindo a presença de abundante biotita e ausência de hornblenda entre os minerais máficos). A notável semelhança em termos de elementos traços, evidenciada pelo aranhograma para o granodiorito PH-192 (Fig. 6A), pode significar que, ao menos no caso desta amostra, existe algum vínculo genético com o BPI, seja através de processos de contaminação (embora os baixos teores de $\mathrm{K}$ não apoiem totalmente a hipótese, conforme discutido acima), seja por sua derivação de um magma cálcioalcalino ligeiramente distinto. Por outro lado, em vista de seu caráter bastante heterogêneo e sua íntima associação com os 

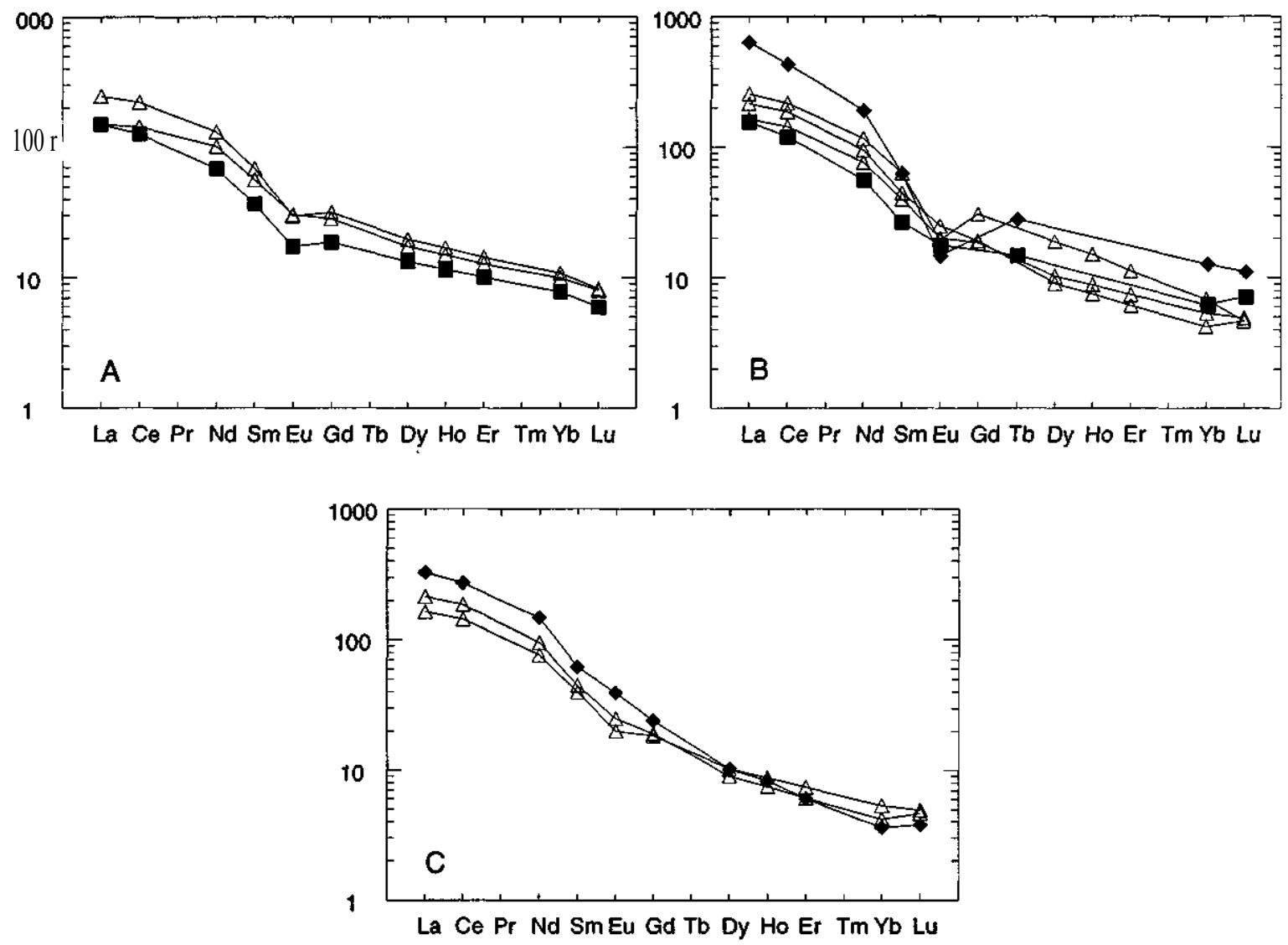

Figura 5 - Padrões de ETR para rochas do Batólito Pinhal-Ipuiúna (BPI) e granitóides circunvizinhos, normalizados pelos valores condríticos de Boynton (1984). A: triângulos vazios = granitóides do BPI(PH-145, PH-01); quadrados cheios = biotita granitóide porfirítico (PH-192). B: triângulos vazios - granitóides do BPI (PH-143, PH-158A, SC-29); granitos tipo Pinhal =losangos cheios (PH-12C), quadrados cheios (SC-77B). C: triângulos vazios = granitóides do BPI (PH-143, PH-158A); losangos cheios $=$ monzonito Maravilha $(\mathrm{PH}-173 \mathrm{~B})$.

Figure 5 - REE patterns for rocks from the Pinhal-Ipuiúna batholith (BPI) and adjacent granitoids, normalized by the chondritic values of Boynton (1984). A: open triangles = BPI granitoids (PH-145, PH-01); closed squares = porphyritic biotite granitoids $(\mathrm{PH}-192)$. B: open triangles = BPI granitoids $(\mathrm{PH}-143$, $\mathrm{PH}-158 \mathrm{~A}$, SC-29); Pinhal-type granites = closed diamonds (PH-12C), closed squares (SC-77B). C: open triangles = BPI granitoids (PH-143, PH-158A); closed diamonds = Maravilha monzonite (PH-172B).

granitos equigranulares tipo Pinhal, parece menos provável que os biotita monzogranitos porfiriticos reunidos na mesma unidade (para os quais o espectro de elementos traços analisados é restrito) tenham algum tipo de vínculo com o BPI.

As características químicas dos biotita granitos tipo Pinhal permitem uma fácil distinção com relação aos tipos mais fracionados do BPI, em particular devido aos teores mais baixos de $\mathrm{Ca}$ e $\mathrm{Sr}$, mais altos de $\mathrm{Zr}$, $\mathrm{Rb}$ e Fe, mg\# mais baixos e padrões de ETR mais fracionados. O caráter fracionado desses granitos e suas composições modais próximas às do mínimo granítico são consistentes com sua origem por anatexia crustal. As características químicas dos granitos tipo Pinhal são comparadas às de outros granitos anatéticos contemporâneos presentes regionalmente em outro trabalho (Janasi 1997), onde se infere sua origem por fusão de protolitos metaluminosos de composição tonalítica-granodiorítica induzida pela quebra de biotita a temperaturas da ordem de $850^{\circ} \mathrm{C}$. As variações químicas observadas entre os grupos bge e bge/i parecem revelar contrastes em termos de área-fonte e/ou mecanismos de extração dos magmas (maiores teores de ETRL e Zr em bge/i revelam maior temperatura de fusão ou simplesmente que a velocidade de extração dos magmas que formaram os granitos do grupo bge foi maior que a velocidade de dissolução dos minerais que continham esses elementos particularmente zircão e allanita?).
Os monzonitos Maravilha constituem um conjunto modal e quimicamente bastante peculiar até então desconhecido na área estudada. É claramente distinto da tendência composicional do BPI, mas seu posicionamento estratigráfico é ainda incerto. Embora texturalmente lembrem os sienitos potássicos tardi-orogênicos que afloram pouco a norte, perfazendo os maciços Pedra Branca e Capituva (Janasi 1993), esses monzonitos são localmente invadidos por biotita granitos equigranulares médios que parecem corresponder aos granitos tipo Pinhal; neste caso, é forçoso admitir uma idade mais antiga, não necessariamente muito distinta da idade do BPI.

Algumas feições químicas dos monzonitos Maravilha são também reminescentes daquelas apresentadas pelos sienitos Pedra Branca e Capituva, em particular o padrão de ETR da amostra PH-173B (caráter fortemente fracionado e ausência de anomalia negativa de Eu) e os teores altos de $\mathrm{Ba}$, $\mathrm{Sr}$ e $\mathrm{Zr}$. Certas peculiaridades químicas dos sienitos potássicos, contudo, não são observadas nos monzonitos estudados; em especial, os teores de Ti e particularmente $\mathrm{P}_{2} \mathrm{O}_{5}$ são sensivelmente mais baixos nos monzonitos Maravilha.

Agradecimentos Este trabalho é parte de uma Tese de Doutoramento, que contou com o apoio financeiro da FAPESP (Procs. 90/0940-0 e 93/3623-3) e da FINEP (Proc. 42.86.091.00). 

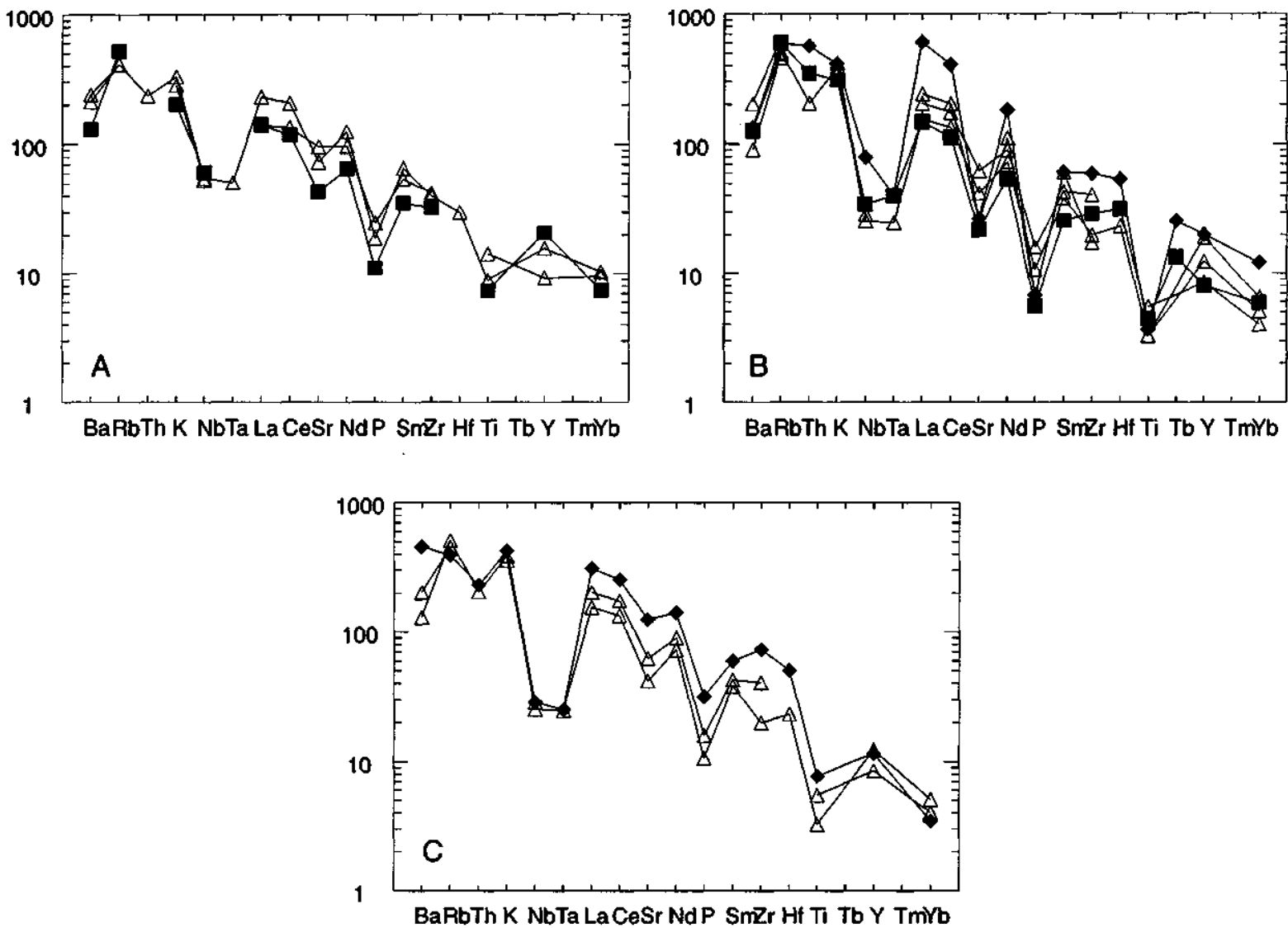

Figura 6 - Padrões de elementos incompatíveis para rochas do Batólito Pinhal-Ipuiúna e granitóides circunvizinhos, normalizados pelos valores condríticos de Thompson et al (1984). Simbolos como na Fig. 5.

Figure 6 - Incompatible-element patterns for rocks from the Pinhal-Ipuiúna batholith (BPI) and adjacent granitoids, normalized by the chondritic values of Thompson et al. (1984). Symbols as in Fig. 5.

\section{REFERÊNCIAS}

BOYNTON, W.V. 1982. Cosmochemistry of the rare-earth elements: meteorite studies. In: P. HENDERSON Ed. Rare-earth Elements Geochemistry. Amsterdam, Elsevier. p. 63-114.

CAMPOS NETO, M.C. 1985. Evolução do pré-Cambriano paulista e regiões adjacentes. In: SIMPOSIO REGIONAL DE GEOLOGIA, 5, São Paulo, 1985. Atas... São Paulo, SBG-NSP. v. 2, p. 561-571.

CAMPOS NETO, M.C.; BASEI, M.A.S.; ALVES, F.R. \& VASCONCELLOS A.C.B.C. 1984. A Nappe de Cavalgamento Socorro (SP-MG). In: CONGR. BRÁS. GEOL., 33, Rio de Janeiro, 1984. Anais... Rio de Janeiro, SBG. v. 4, p. 1.809-1.822

HADDAD, R.C. 1995. O Batólito Granitóide Pinhal-Ipuiúna (SP-MG): um exemplo do magmatismo cálcio-alcalino potássico neoproterozóico no sudeste brasileiro. São Paulo, 270 p. (Tese de Doutoramento, IG/USP)

HADDAD, R.C. \& JANASI, V.A. 1992. Petrografia do Batólito Granitóide Pinhal-Ipuiúna (SP-MG). In: CONGR. BRÁS. GEOL., 37, São Paulo, 1992. Boletim de Resumos Expandidos... São Paulo, SBG. v.l, p. 395-395.

HADDAD, R.C.; JANASI, V.A. \& ULBRICH, H.H.G.J. 1996. Petrologiae geoquímica do Batólito Granitóide Pinhal-Ipuiúna (SP-MG). In CONGR. BRÁS. GEOL., 39, Salvador, 1996. Anais... Salvador, SBG. v. 6, p. $433-436$.

JANASI, V. A. 1992. Rochas sieníticas e mangerítico-charnoquíticas neoproterozóicas da região entre Caldas e Campestre (MG): Aspectos Petrológicos. São Paulo, 298 p. (Tese de Doutoramento, IG/USP).

JANASI, V.A. 1997. Crustal anatexis and granite genesis during the Neoproterozoic metamorphism in the Socorro-Guaxupé Thrust Nappe, Southeastern Brazil: a preliminary survey. Revista Brasileira de Geociências (este volume).

JANASI, V.A. \& ULBRICH, H.H.G.J. 1985. Avaliação das informações disponíveis para granitóides do Estado de São Paulo. In: SIMPÓSIO REGIONAL DE GEOLOGIA, 5, São Paulo, 1985. Atas... São Paulo, SBG-NSP. v. 1, p. 133-146.
JANASI, V.A. \& ULBRICH, H.H.G.J. 1991. Late Proterozoic granitoid magmatism in the state of São Paulo, Southeastern Brazil. Prec. Res. 51: 524-534

JANASI, V.A.; ANDRADE, S. \& ULBRICH, H.H.G.J. 1996. A correção de drift e a análise de elementos maiores, menores e traços em ICP-AES com espectrômetro sequencial. Boletim IG-USP (Série Científica), no prelo.

THOMPSON, R.N.; MORRISSON, M.A.; HENDRY, G.L. \& PARRY, S.J. 1984. An assessment of the relative roles of crust and mantle in magma génesis: an elemental approach. Philosophycal Transactions of the Royal Society of London, A310: 549-590.

VASCONCELLOS, A.C.B.C. \& JANASI, V.A. 1989. Mapeamento faciológico do batólito granitóide cálcio-alcalino de Pinhal-Ipuiúna (SPMG). In: SIMP. GEOL. MINAS GERAIS, 6, Belo Horizonte, 1989. Atas... Belo Horizonte, SBG-NMG. p. 65-69.

VASCONCELLOS, A.C.B.C; HARRIS, NB.W \& TINDLE A.G. 1991. The relationship between metamorphism and tectonics: evidence from the Socorro-Guaxupé Thrust Nappe, southeastern Brazil. In: P. TUISKU \& K.LAAJAKI Eds. Metamorphism, Deformation and Structure of the Crust. Res Terrae. Finland, University of Oulu. v. A-5, p. 86.

WERNICK, E. \& PENALVA, F. 1980. Contribuição à geologia do Grupo Pinhal (SP e MG). Rev. Bras. Geoc., 10: 43-62.

WINTERS, A.A.M. 1981. A geologia do maciço sienítico da Pedra Branca, Caldas-MG. São Paulo, 92 p. (Dissertação de Mestrado, IG/USP).

Manuscrito A889

Recebido em 15 de novembro de 1996 Revisão dos autores em 15 de abril de 1997 Revisão aceita em 15 de junho de 1997 